\title{
Reversibility of fibrosis, inflammation, and endoplasmic reticulum stress in the liver of rats fed a methionine-choline-deficient diet
}

\author{
Yong-ping $\mathrm{Mu}^{1,2}$, Tomohiro Ogawa ${ }^{1}$ and Norifumi Kawada ${ }^{1}$
}

Fatty liver disease has become a health problem related to metabolic syndrome worldwide, although its molecular pathogenesis requires further study. It is also unclear whether advanced fibrosis of steatohepatitis will regress when diet is controlled. The aim of this study was to investigate whether the resolution of fibrosis occurs in steatohepatitis induced by a methionine-choline-deficient diet (MCDD). Manifestation of endoplasmic reticulum (ER) stress in this model was also studied. Nonalcoholic steatohepatitis with advanced fibrosis was induced in rats by feeding them an MCDD for 10 weeks. Instead of MCDD, a methionine-choline control diet (CD) was given for the last 2 weeks to the experimental group. Fibrosis and inflammation were determined by tissue staining. Protein and gene expressions were determined by immunoblotting and quantitative reverse transcription-PCR (RT-PCR), respectively. Expressions of caspase-7, caspase-12, glucose-regulated protein 78 (GRP78), and protein disulfide isomerase were evaluated to clarify the presence of ER stress. Changing the diet from MCDD to CD triggered the reduction of fat in hepatocytes, a decrease in inflammatory gene expression and oxidative stress, and regression of fibrosis accompanied by the disappearance of activated stellate cells and macrophages. Immunohistochemistry, immunoblotting, and RT-PCR analysis all indicated the occurrence of ER stress in steatohepatitis, while it recovered immediately after changing the diet from MCCD to CD. The ratio of hepatocyte proliferation/apoptotis increased significantly during the recovery stage. This simple experiment clearly shows that changing the diet from MCDD to a normal diet (CD) triggers the resolution of hepatic inflammatory and fibrotic reactions and hepatocyte apoptosis, suggesting that MCDD-induced steatohepatitis is also reversible. ER stress appears and disappears in association with the generation and regression of steatohepatitis, respectively, with fibrosis.

Laboratory Investigation (2010) 90, 245-256; doi:10.1038/labinvest.2009.123; published online 30 November 2009

KEYWORDS: caspase; cytoglobin; hepatic stellate cells; hepatocytes; Kupffer cells; oxidative stress

Nonalcoholic fatty liver disease (NAFLD) is a relatively newly defined hepatic sequela of obesity and type II diabetes mellitus, ${ }^{1-3}$ and it is one of the most common causes of chronic liver disease in many countries. ${ }^{4}$ A number of studies have identified a significant correlation between hepatic steatosis and fibrosis. ${ }^{5-7}$ NAFLD covers a progressive spectrum of liver pathologies from simple steatosis to nonalcoholic steatohepatitis (NASH), which is characterized by necroinflammation and fibrosis, and, subsequently, by cirrhosis. ${ }^{8}$ It is also speculated that NASH may progress to hepatocellular carcinoma. $^{9-11}$

Although adipocytokines, cytokines, and free fatty acids (FFAs) derived from peripheral and visceral fat tissues, which are known as mediators of metabolic syndrome, are assumed to contribute to the initiation of inflammatory reactions in the liver, the link between the development of hepatic steatosis and fibrosis is still poorly understood. ${ }^{12}$ Furthermore, whether the regression of liver fibrosis caused by NASH occurs after controlling diet has not been proven, but the reversibility of liver fibrosis has been evidenced in patients who have successfully achieved the eradication of hepatitis C virus after interferon therapy. ${ }^{13,14}$

Over the past decade, it has become clear that obesity is associated with the activation of cellular stress signaling and inflammatory pathways. ${ }^{15-17}$ A key cell organelle in cellular stress response is the endoplasmic reticulum (ER), a membranous network that functions in the synthesis and processing of secreted and membranous proteins. Certain

'Department of Hepatology, Graduate School of Medicine, Osaka City University, Osaka, Japan and ${ }^{2}$ Shanghai Public Health Clinical Centre, Shanghai, China

Correspondence: Dr N Kawada, MD, PhD, Department of Hepatology, Osaka City University, Graduate School of Medicine, 1-4-3, Asahimachi, Abeno, Osaka 545-8585, Japan.

E-mail: kawadanori@med.osaka-cu.ac.jp

Received 26 March 2009; revised 2 September 2009; accepted 10 September 2009 
pathological stress conditions disrupt ER homeostasis and lead to the accumulation of unfolded or misfolded proteins in the ER lumen, known as ER stress, resulting in the activation of signal transduction systems. ${ }^{18-20}$ ER stress is caused by glucose or nutrient deprivation, viral infections, lipids, increased synthesis of secretory proteins, and expression of mutant or misfolded proteins, and has been recently implicated in human diseases, such as Alzheimer's disease, Parkinson's disease, diabetes mellitus, and liver disease. ${ }^{21-24}$

In this study, a rat steatohepatitis model induced by a methionine-choline-deficient diet (MCDD) for 10 weeks was used to obtain evidence for the resolution of fibrosis in fatty liver after changing the diet to a methionine-choline control diet (CD). The manifestation of ER stress was also studied. The results of this study clearly indicated that a dietary change from MCDD to $\mathrm{CD}$ immediately initiates tissue remodeling, which is associated with the cessation of cellular apoptosis and ER stress.

\section{MATERIALS AND METHODS Materials}

Mouse monoclonal antibody against $\alpha$-smooth muscle actin $(\alpha$-SMA, Clone 1A4) and mouse monoclonal antibody against 5-bromo-2-deoxyuridine (BrdU, Clone 1BU33, 1:1000) were obtained from Sigma Chemical (St Louis, MO, USA). Rat monoclonal antibody against caspase- 12 and goat polyclonal antibodies against glucose-regulated protein 78 (GRP78) were purchased from Santa Cruz Biotechnology (Santa Cruz, CA, USA). Rabbit polyclonal antibodies against caspase-7, rabbit polyclonal antibodies against cleaved caspase-7 (Asp198), and rabbit polyclonal antibodies against protein disulfide isomerase (PDI) were obtained from Cell Signaling Technology (Danvers, MA, USA). Mouse monoclonal antibody against CD68 (Clone, KP1) was purchased from Dako Denmark A/S (Glostrup, Denmark). Mouse monoclonal antibody against heme oxygenase-1 (HO-1, Hsp32) was obtained from Assay Designs (Ann Arbor, MI, USA). Mouse monoclonal antibody against 4-hydroxy-2nonenal (4-HNE) was purchased from the Japan Institute for the Control of Aging (Shizuoka, Japan). Mouse monoclonal antibody against glyceraldehyde-3-phosphate dehydrogenase (GAPDH) was obtained from Chemicon International (Temecula, CA, USA). Rabbit anti-cytoglobin antibodies were produced in our laboratory as described previously. ${ }^{25}$ Horseradish peroxidase (HRP)-conjugated polyclonal rabbit anti-goat immunoglobulins, HRP-conjugated polyclonal rabbit anti-mouse immunoglobulins, HRP-conjugated polyclonal rabbit anti-rat immunoglobulins, and HRP-conjugated polyclonal swine anti-rabbit immunoglobulins were obtained from Dako Denmark A/S. Hybond-ECL nitrocellulose membranes and ECL detection reagent were obtained from Amersham Pharmacia Biotech (Buckinghamshire, UK). All other reagents were purchased from Sigma Chemical or Wako Pure Chemical.

\section{Animals and Experimental Protocol}

Pathogen-free male Wistar rats (7-8 weeks of age) were obtained from SLC (Shizuoka, Japan). Animals were housed at a constant temperature and supplied with laboratory chow and water ad libitum. The experimental protocol was approved by the Animal Research Committee of Osaka City University (Guide for Animal Experiments, Osaka City University).

The rats were fed a CD (group C, $n=5$ ) or MCDD (group $\mathrm{M}, n=5$ ) for 10 weeks. The contents of MCDD and CD are listed in Supplementary Table 1. A recovery model (group R, $n=5$ ) was produced by administering MCDD for 8 weeks and thereafter CD for 2 weeks. During the experimental period, individual body weights were recorded twice per week (see Supplementary Table 2).

\section{Sample Harvesting}

At the end of the tenth week, rats were killed under ether anesthesia, and the portal vein was cannulated using an $18-\mathrm{G}$ Teflon catheter. Blood samples were collected from the inferior vena cava, centrifuged at 3000 r.p.m. for $30 \mathrm{~min}$ at $4^{\circ} \mathrm{C}$, and the obtained sera were kept at $-70^{\circ} \mathrm{C}$ until further use for serum chemistry tests. The liver of each animal was perfused with $100 \mathrm{ml}$ of phosphate-buffered saline ( $\mathrm{pH}$ 7.0) to remove blood and then washed with ice-cold saline, dried using filter paper, and weighed in a wet state. A portion of the liver was fixed with $4 \%$ paraformaldehyde, embedded in paraffin, and frozen. Another portion of the liver was snapfrozen in liquid nitrogen and stored at $-70^{\circ} \mathrm{C}$ until use for reverse transcription-PCR (RT-PCR) and immunoblots.

\section{Serum Chemistries}

Serum levels of alanine aminotransferase (ALT), aspartate aminotransferase (AST), triglycerides (TGs), and FFAs were measured at Special Reference Laboratories (Osaka, Japan).

\section{Histochemical and Immunohistochemical Analyses of the Rat Liver}

Paraformaldehyde-fixed specimens were cut into 5- $\mu \mathrm{m}$-thick sections and stained for $1 \mathrm{~h}$ with $0.1 \%(\mathrm{w} / \mathrm{v})$ Sirius Red (Direct Red 80; Aldrich, Milwaukee, WI, USA), Oil red O, or hematoxylin and eosin (H\&E). Immunohistochemistry was performed according to the methods described elsewhere. ${ }^{26}$ Briefly, sections were deparaffinized, washed, and preincubated in blocking solution, followed by incubation with anti-4-HNE (15 $\mu \mathrm{g} / \mathrm{ml})$, HO-1 (1:50), CD68 (1:100), $\alpha$-SMA (1:100), cytoglobin (1:400), or caspase-12 (1:100) antibodies. Sections were then incubated with HRP-conjugated secondary antibodies (1:1000), washed, covered with DAB, and counterstained with hematoxylin. Some of the immunostainings were performed at the Biopathology Institute (Oita, Japan). The red area on Oil red O staining was image analyzed by LuminaVision (Mitani Corporation, Tokyo, Japan). 


\section{TdT-Mediated dUTP Nick-End Labeling Assays}

For the detection of apoptotic cells, paraffin-embedded sections were stained with the TdT-Mediated dUTP Nick-End Labeling (TUNEL) technique using an In Situ Apoptosis Detection kit (Takara Shuzo, Ohtsu, Japan) according to the manufacturer's instructions. For semi-quantitative analysis, the number of TUNEL-positive cells was counted in five randomly selected fields by viewing each slide at a magnification of $\times 400$, and the average number in each group was calculated, as described previously. ${ }^{27}$

\section{BrdU Assay for Hepatocyte Proliferation}

For the detection of hepatocyte proliferation, rats were i.p. injected with BrdU $(100 \mu \mathrm{g} / \mathrm{kg}) 2 \mathrm{~h}$ before being killed. In situ detection of the incorporation of BrdU into the nuclei was conducted immunohistochemically. ${ }^{28}$ For semi-quantitative analysis, as for TUNEL, the number of BrdU-positive cells was counted in five randomly selected fields by viewing each slide at a magnification of $\times 200$, and the average number in each group was calculated.

\section{Quantitative RT-PCR}

mRNA expressions of tumor necrosis factor-alpha (TNF- $\alpha$ ), transforming growth factor-beta 1 (TGF- $\beta 1$ ), $\alpha$-SMA, collagen 1A2 (COL1A2), matrix metalloproteinases (MMPs)-2, -9 , and -13 , tissue inhibitor of MMP-1 (TIMP-1), caspases-3, $-7,-9$, and -12, GRP78, interleukin-6 (IL-6), BAX, BAK, Bcl$\mathrm{xl}, \mathrm{Bcl}-2$, and ERp57 were assessed by quantitative RT-PCR. Total RNA was extracted from liver tissues using Isogen (Nippon Gene, Tokyo, Japan). ${ }^{29}$ The expression of mRNA was measured using TaqMan One-Step RT-PCR Master Mix Reagents (Applied Biosystems, Foster City, CA, USA) or using the One-Step SYBR RT-PCR Kit (Perfect Real Time; Takara Bio, Ohtsu, Japan), and Applied Biosystems Prism 7700 (Applied Biosystems) according to a previously reported procedure. ${ }^{27}$ Primers and oligonucleotide probes were designed using Primer Express (Sigma Chemical), and are listed in Table 1. Each PCR amplification was performed on five rats in both experimental and control groups. Individual gene expression was normalized by GAPDH. The conditions for the TaqMan One-Step RT-PCR were as follows: $30 \mathrm{~min}$ at $48^{\circ} \mathrm{C}$ (stage 1, RT), 10 min at $95^{\circ} \mathrm{C}$ (stage 2, RT inactivation and Ampli Taq Gold activation), and then 40 cycles of amplification for $15 \mathrm{~s}$ at $95^{\circ} \mathrm{C}$ and $1 \mathrm{~min}$ at $60^{\circ} \mathrm{C}$ (stage 3, PCR). The conditions for the One-Step SYBR RT-PCR (Perfect Real Time) were as follows: an initial step of $15 \mathrm{~min}$ at $42^{\circ} \mathrm{C}, 2 \mathrm{~min}$ at $95^{\circ} \mathrm{C}$, and then 40 amplification cycles of denaturation at $95^{\circ} \mathrm{C}$ for $15 \mathrm{~s}$, and annealing and extension at $60^{\circ} \mathrm{C}$ for $1 \mathrm{~min}$.

\section{Immunoblot Analysis}

Some protein levels were assessed by immunoblot analysis, as described previously. ${ }^{29}$ The liver tissue was lysed by RIPA buffer containing $50 \mathrm{mM}$ Tris- $\mathrm{HCl}(\mathrm{pH} 7.2), 150 \mathrm{mM} \mathrm{NaCl}$, $1 \%$ NP-40, 0.1\% SDS, $1 \mathrm{mM}$ EDTA, and $1 \mathrm{mM}$ PMSF and then homogenized in ice-cold water. After centrifugation for
$10 \mathrm{~min}$ at $4^{\circ} \mathrm{C}$ and 12000 r.p.m., the protein concentration of the obtained supernatant was determined using the Bio-Rad Dc protein Assay Reagent (Bio-Rad, Hercules, CA, USA). Protein was electrophoretically resolved in 10 or $12 \%$ SDS polyacrylamide gel, and successively transferred to HybondECL nitrocellulose membranes. The membranes were blocked by $5 \%$ non-fat dietary milk solution in Tris-buffered saline $(20 \mathrm{mM}$ Tris and $150 \mathrm{mM} \mathrm{NaCl}, \mathrm{pH} 7.4)$ with $0.1 \%$ Tween-20. They were then incubated overnight with primary antibodies at $4{ }^{\circ} \mathrm{C}$ and successively with secondary antibodies at room temperature for $1 \mathrm{~h}$. The following dilutions of primary antibodies were used: mouse monoclonal antibody to $\alpha$-SMA, 1:1000; rabbit polyclonal antibodies to cytoglobin, 1:200; rat monoclonal antibody to caspase-12, 1:200; goat polyclonal antibodies to GRP78, 1:200; rabbit polyclonal antibodies to caspase-7, 1:1000; rabbit polyclonal antibodies to cleaved caspase-7 (Asp198), 1:1000; rabbit polyclonal antibodies against PDI, 1:200; mouse monoclonal antibody to GAPDH, 1:30 000. Immune complexes were visualized using a SuperSignal West Pico Chemiluminescent Substrate (ECL, Pierce, Rockford, IL, USA). Finally, band intensity was determined by scanning video densitometry.

\section{Statistical Analysis}

All results are expressed as mean \pm s.d. Statistical analysis was performed using Student's $t$-test $(P<0.05$ was considered significant).

\section{RESULTS \\ Accumulation of Fat in the Liver and Recovery after Dietary Change}

As shown in Figure 1a and b, Oil red O staining clearly indicated that the MCDD diet (group M) for 10 weeks induced fat accumulation in the liver, especially in hepatocytes. It was also recognized that fat accumulation immediately decreased in group $\mathrm{R}(P<0.01)$, whose diet was changed from MCDD to CD during the last 2 weeks. The serum level of FFA was reduced in group M (183 $\pm 31.6 \mu$ equiv./l) compared with control group C $(274 \pm 35.7 \mu$ equiv./l) and recovery group $\mathrm{R}(267 \pm 36.5 \mu$ equiv./l) $(P<0.01)$. Similarly, the serum level of $\mathrm{TG}$ was reduced in group $\mathrm{M}$ $(4.33 \pm 1.21 \mathrm{mg} / \mathrm{dl})$ compared with control group C $(23.5 \pm 4.95 \mathrm{mg} / \mathrm{dl})$ and group $\mathrm{R} \quad(28.2 \pm 4.97 \mathrm{mg} / \mathrm{dl})$ $(P<0.01)$ (Figure 1c and d, $P<0.01)$. Changes in the body weights of rats in each group are presented in Supplementary Table 2.

\section{Liver Histology and Kupffer Cell Activation}

$\mathrm{H} \& \mathrm{E}$ staining showed that the livers in group $\mathrm{C}$ showed an intact tissue structure, whereas those in group $\mathrm{M}$ showed the apparent vacuolization of hepatocytes, focal necrosis, and inflammatory cell accumulation in the parenchyma. These pathological changes were clearly improved in group $\mathrm{R}$ (Figure 2a). In accordance with this histological recovery, serum levels of AST and ALT were reduced from 97.7 \pm 13.5 
Table 1 Primer pairs and probes used for real-time PCR

\begin{tabular}{lll}
\hline Primer name & Sequence & Note \\
\hline TNF- $\alpha$ & & TaqMan \\
Forward & $5^{\prime}$-GCT CCC TCT CAT CAG TTC CAT G-3' & \\
Reverse & $5^{\prime}$-TAC GGG CTT GTC ACT CGA GT TTG-3' \\
Probe & $5^{\prime}$-CCC AGA CCC TCA CAC TCA GAT CAT CTT C-3'
\end{tabular}

Heme oxygenase-1

SYBR

Green

Forward 5'-CGT GGC AGT GGG AAT TTA TG-3'

Reverse $\quad 5^{\prime}$-AGG CTA CAT GAG ACA GAG TTC ACA-3'

TGF- $\beta 1$

Forward $\quad$ 5'-TGC TTC CGC ATC ACC GT-3'

Reverse 5'-TAG TAG ACG ATG GGC AGT GGC-3'

Probe $\quad 5^{\prime}$-CTG CGT GCC GCA GGC TाT GG-3'

Collagen IA2

Forward

Reverse

Probe

5'-AAG GGT CCT TCT GGA GAA CC-3'

5'-TCG AGA GCC AGG GAG ACC CA-3'

5'-CAG GGT CTT CTT GGT GCT CCC GGT AT-3'

$\alpha-S M A$

Forward

5'-GAG GAG CAT CCG ACC TTGC-3'

Reverse

Probe

MMP-2

Forward

Reverse

Probe

MMP-9

Forward

Reverse

$M M P-13$

Forward

Reverse

TIMP-1

Forward

Reverse
5'-GAC AAT CCT TGC AAT GTG GAT G-3'

5'-TGA CCT GGG ATT TCC AAA AGA G-3'

5'-TCT TCC CCG TGT CCT CAA A-3'

5'-TCA GCC ATC CCT TGC AAA-3'

5'-CCG AGG ACT ATG ACC GGG ATA A-3'

5'-CTT GTT GCC CAG GAA AGT GAA G-3'

5'-TCT GCC CCG AGA CCG CTA TGT CCA-3'

SYBR

Green

$B A X$

Forward

Reverse

SYBR

$B A K$

Green

$$
\text { Forward }
$$

Reverse

SYBR

Green 5'-GAG CCC ATG AGG ATC TGA TCT-3'
$B C|-x|$

Forward 5'-TGCGTGGAAAGCGTAGACAAGGA-3'

Reverse
5'-TAAAGTGCCCGAGCTGATCAGAACC-3'

5'-CCTGGTCTTGGATCCAGACAAGCA-3'

5'-GAGTITGCGTAGAGACCCCATCCT-3'

5'-CCACAAATTGGCCCAACAGAACCA-3'

SYBR

Green

5'-TGG ACA TTG GTT CTG GCA GAG-3' 5'-GTG TAT GCC ATA TCT GCA TGT CTC-3'

SYBR

Green

SYBR

Green

SYBR

Green

SYBR

Green

SYBR

Green

SYBR

Green

SYBR

Green 
Table 1 Continued

\begin{tabular}{|c|c|c|}
\hline Primer name & Sequence & Note \\
\hline \multirow[t]{2}{*}{$\mathrm{BCl}-2$} & & SYBR \\
\hline & & Green \\
\hline Forward & 5'-TCGCGACTITGCAGAGATGTCC-3' & \\
\hline Reverse & 5'-ACCCCATCCCTGAAGAGTTCCT-3' & \\
\hline \multicolumn{3}{|l|}{ IL-6 } \\
\hline Forward & 5'-TGT CTC GAG CCC ACC AGG-3' & TaqMan \\
\hline Reverse & 5'-TGC GGA GAG AAA CTT CAT AGC TG-3' & \\
\hline \multirow[t]{2}{*}{ Probe } & 5'-CGA AAG TCA ACT CCA TCT GCC CTT CAG G- & \\
\hline & $3^{\prime}$ & \\
\hline \multicolumn{3}{|l|}{ STAT3 } \\
\hline \multirow[t]{2}{*}{ Forward } & $5^{\prime}$-CAA TAC CAT TGA CCT GCC GAT-3' & SYBR \\
\hline & & Green \\
\hline Reverse & 5'-CCC CGT TAT TTC CAA ACT GC-3' & \\
\hline GAPDH & & TaqMan \\
\hline Forward & 5'-AAG ATG GTG AAG GTC GGT GTG-3' & \\
\hline Reverse & $5^{\prime}$-GAA GGC AGC CCT GGT AACC-3' & \\
\hline Probe & $5^{\prime}$-CGG ATT TGG CCG TAT CGG ACGC-3' & \\
\hline \multirow[t]{2}{*}{ GAPDH } & & SYBR \\
\hline & & Green \\
\hline Forward & 5'-AAT GCA TCC TGC ACC ACC AAC TGC-3' & \\
\hline Reverse & $5^{\prime}$-GGA GGC CAT GTA GGC CATG AGG TC-3' & \\
\hline
\end{tabular}

and $98.5 \pm 14.9 \mathrm{IU} / \mathrm{ml}$ in group $\mathrm{M}$ and from $51.2 \pm 13.8$ and $35.4 \pm 3.3 \mathrm{IU} / \mathrm{ml}$ in group $\mathrm{R}$, respectively $(P<0.01)$. Cells positive for CD68, a marker of activated Kupffer cells, increased in number (Figure $2 \mathrm{~b}$ ) in group $\mathrm{M}$. The expression of TNF- $\alpha$ mRNA, which is known to be derived from activated Kupffer cells in the liver, increased to 2.5-fold in group $\mathrm{M}$ (Figure 2e, $P<0.01$ ) compared with group $\mathrm{C}$, and returned to the normal range in group $\mathrm{R}(P<0.01)$. These results indicate that the change in diet from MCDD to $\mathrm{CD}$ reduced inflammatory reactions, Kupffer cell activation, and AST/ALT release from hepatocytes.

\section{Oxidative Stress and its Recovery in Steatohepatitis}

We used the immunostaining of 4-HNE to detect the production of oxidative aldehyde by lipid peroxidation in the liver. As shown in Figure 3a, the control liver of group C exhibited negligible staining by anti-4-HNE antibodies. In contrast, the liver in group $\mathrm{M}$ showed brown-colored hepatocytes and stained cells also accumulated at necrotic foci (magnified area). The number of 4-HNE-positive cells and the amount of granulomatous accumulation in cells, presumably macrophages, were clearly reduced in group R.

These results were reproduced on immunostaining of HO-1. As shown in Figure 3b, HO-1 expression is restricted in hepatic sinusoids, presumably in Kupffer cells (magnified area). However, in group M, HO-1-positive cells additionally led to an aggregation of cells next to vacuolized hepatocytes (magnified area). These reactions immediately disappeared in group R. In accordance with these results, HO-1 mRNA expression determined by RT-PCR was significantly augmented in group $\mathrm{M}$ compared with group C $(5.19 \pm 1.08 \mathrm{vs}$ $3.13 \pm 0.26$, respectively, $P<0.01)$ and returned to the normal level in group $\mathrm{R}$.

Taken together, it can be stated that the accumulation of Oil red O-stained lipids, 4-HNE, and CD68- and HO-1positive macrophages by administering an MCDD diet generates oxidative stress and hepatocyte damage (increase in AST and ALT levels), resulting in inflammatory gene expression, such as TNF- $\alpha$. However, switching the diet from MCDD to $C D$ immediately triggers the inhibition of inflammatory reactions.

\section{Regression of Fibrosis and Hepatic Stellate Cell Activation in Steatohepatitis}

Sirius Red staining (Figure 4a) clearly revealed collagen deposition with $\mathrm{C}-\mathrm{C}$ and $\mathrm{P}-\mathrm{C}$ bridges, near to cirrhosis, in the fibrotic septum of group $\mathrm{M}$, although collagen deposition was observed only around veins in the intact liver (group C). An immediate and marked recovery of this advanced fibrosis was observed in group $\mathrm{R}$, indicating that the change in diet from MCDD to CD triggers the regression of fibrosis in the liver within 2 weeks.

Immunohistochemistry of $\alpha$-SMA and cytoglobin, markers of activated stellate cells and liver myofibroblasts, showed that hepatic fibrotic cell activation occurred in group $\mathrm{M}$, whereas the process ceased immediately in group R (Figure $4 \mathrm{~b}$ and c). Immunoblot analyses confirmed these immunohistochemical observations (Figure 4d). Furthermore, as shown in Figure 4e, RT-PCR analyses indicated that mRNA expressions of all $\alpha$-SMA, TGF- $\beta 1$, Col1A2, TIMP- 1 , MMP-2, and MMP-9 increased significantly in group $M$, and thereafter returned to the original level in group R. Conversely, the expression of MMP-13 decreased significantly in group $\mathrm{M}(0.98 \pm 0.30$ vs $3.39 \pm 1.24, P<0.01)$ and recovered significantly in group $\mathrm{R}(2.30 \pm 1.11)$. Thus, the recovery of fibrosis is evident at levels of histology, fibrotic protein, and fibrotic gene expression after switching the diet from MCDD to CD.

The Change of Hepatocyte Apoptosis and Proliferation TUNEL staining showed that the number of apoptotic hepatocytes slightly increased in group $\mathrm{M}$ compared with group C $(68.2 \pm 15.9$ vs $40.3 \pm 8.33$ cells per field, respectively, $P<0.05)$, whereas it decreased significantly in group $R$ (48.0 \pm 6.48 cells per field) (Figure $5 \mathrm{a}$ and $\mathrm{c}$ ). 

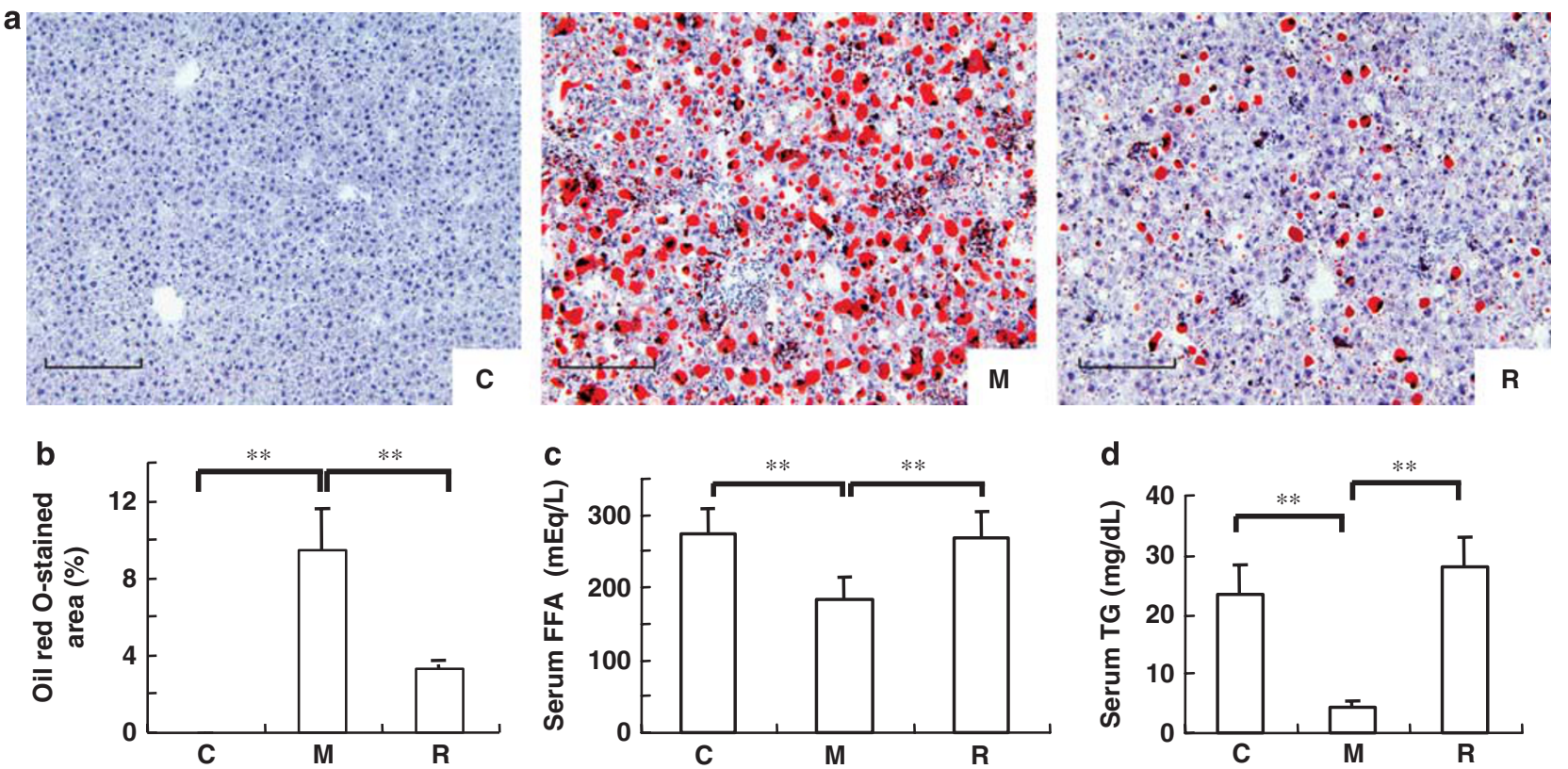

Figure 1 Oil red $O$ staining in the liver and the serum level of FFA and TG. (a) Oil red O staining $(\times 200)$. Five sections per group were measured. Bar, $25 \mu$ m. (b) Percentage of Oil red O-stained area was determined using an image analyzer (LuminaVision). Group C, $0 \%$; group $\mathrm{M}, 9.45 \%$ ( $P<0.01$ compared with

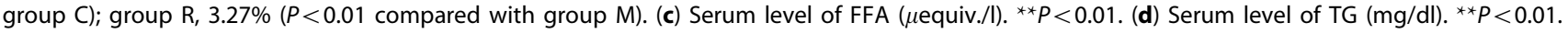
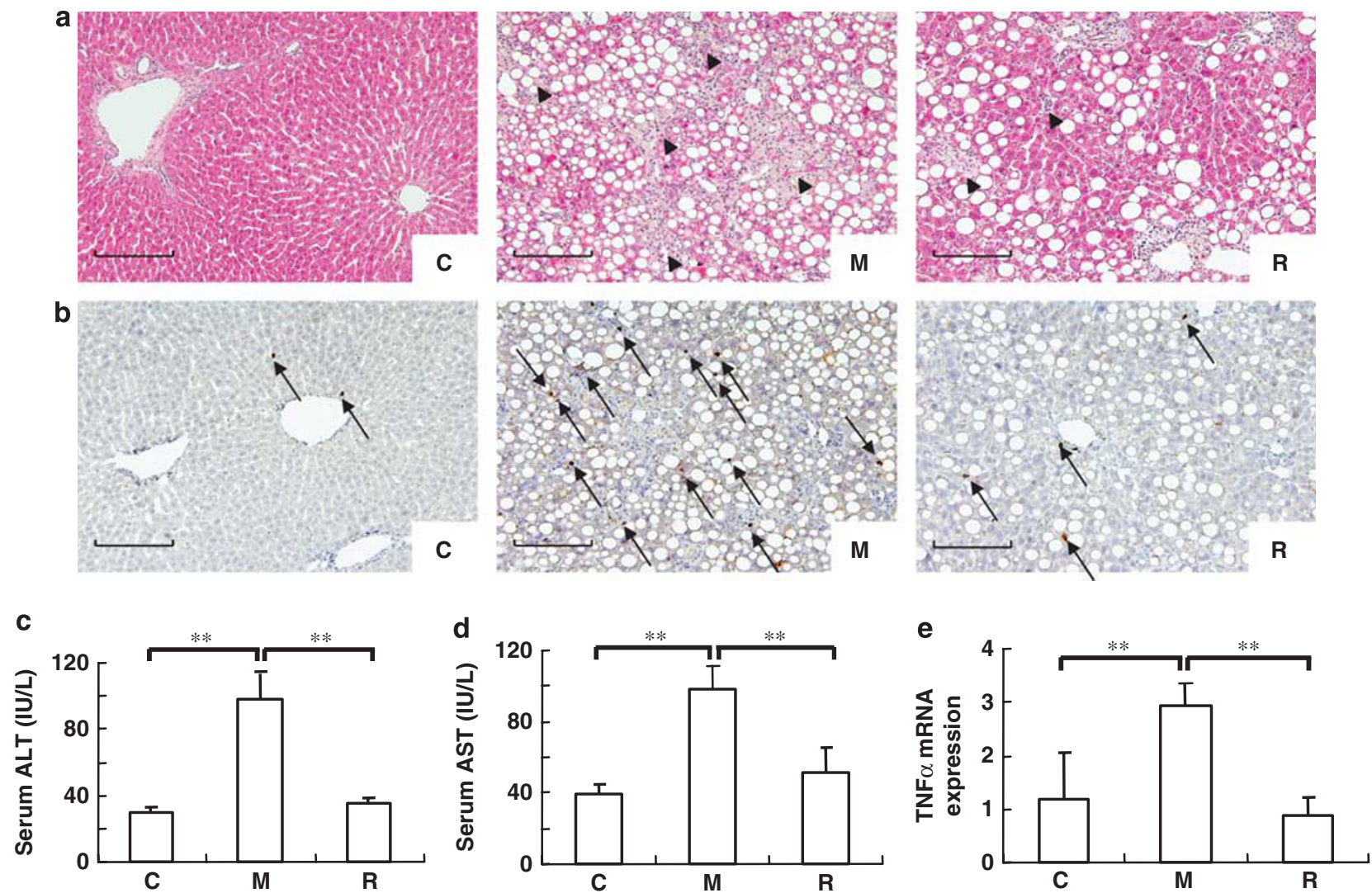

Figure 2 Kupffer cell activation and inflammation. (a) H\&E staining $(\times 200)$. In group $M$, hepatocytes with fatty degeneration and inflammatory cell foci (arrowheads) were distributed in the parenchyma, whereas their number decreased in group R. Bar, $25 \mu \mathrm{m}$. (b) CD68 immunostaining (arrows) $(\times 200)$. CD68, a macrophage marker and low-density lipoprotein binding site, was rare in group C, whereas CD68-positive cells increased in number in group M, and decreased in group R. Bar, $25 \mu \mathrm{m}$. (c and d) Serum levels of ALT and AST. (e) The relative TNF- $\alpha$ mRNA level measured by RT-PCR. The TNF- $\alpha$ mRNA level was normalized by the GAPDH mRNA level. 

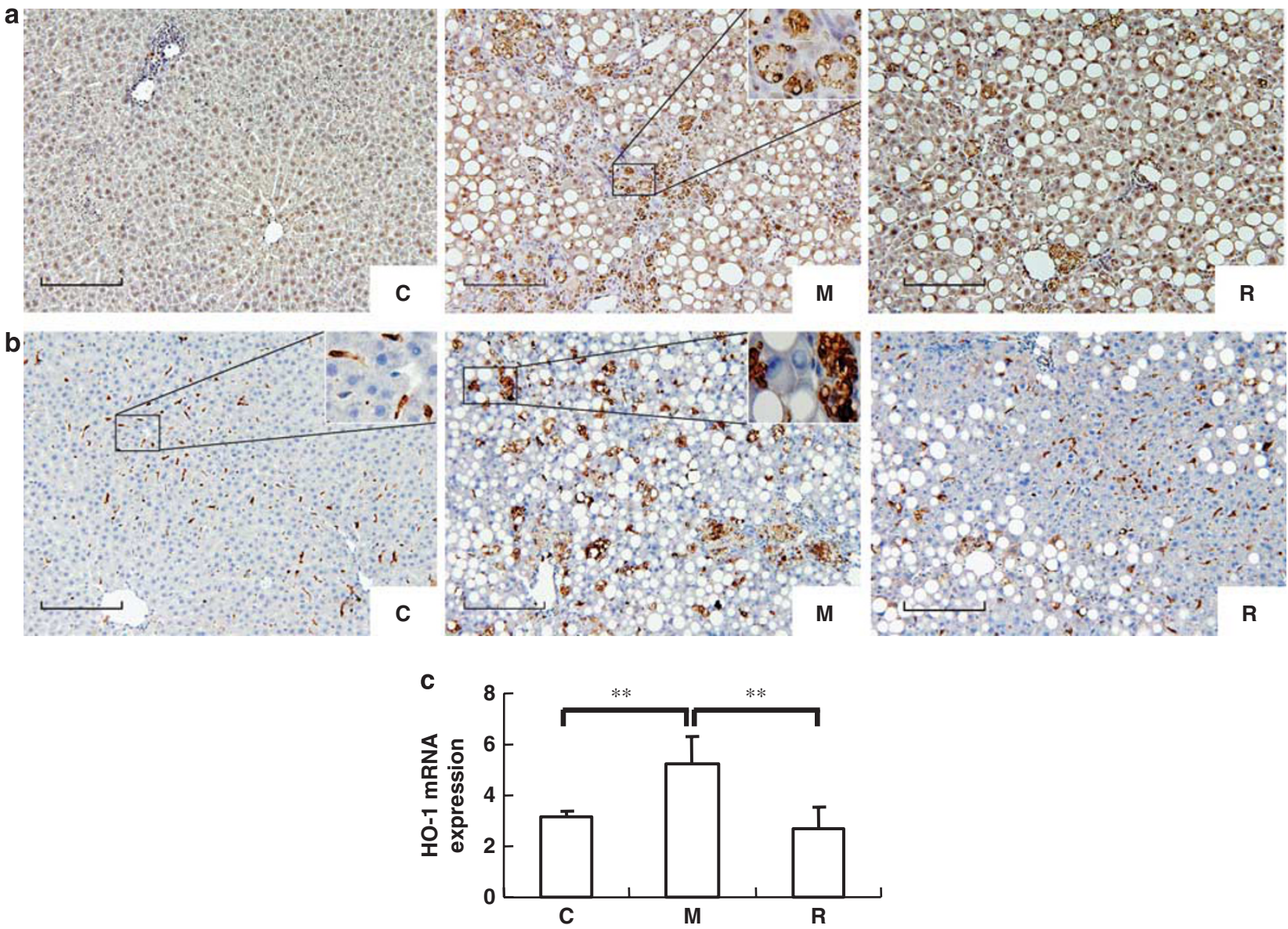

Figure $3 \mathrm{Immunohistochemistry} \mathrm{of} \mathrm{4-HNE} \mathrm{and} \mathrm{HO-1,} \mathrm{and} \mathrm{the} \mathrm{expression} \mathrm{of} \mathrm{HO-1} \mathrm{mRNA.} \mathrm{(a)} \mathrm{Immunohistochemistry} \mathrm{of} \mathrm{4-HNE}(\times 200)$. Bar, $25 \mu$ m. There is a magnified view of the squared area $(\times 1000)$. Foamed macrophages are evident. (b) Immunohistochemistry of HO-1 $(\times 200)$. The box shows a higher magnification of the squared area. Bar, $25 \mu \mathrm{m}$. (c) HO-1 mRNA level. ${ }^{\star *} P<0.01$. The HO-1 mRNA level was normalized by the GAPDH mRNA level.

Conversely, the in situ BrdU incorporation assay showed that the number of proliferated hepatocytes underwent no marked changes in group $\mathrm{M}$ compared with group C $(7.5 \pm 3$ vs $7.6 \pm 1.0$ cells per field, respectively, $P>0.05)$, whereas it increased significantly in group $\mathrm{R}(17.2 \pm 4.35$ cells per field) (Figure $5 \mathrm{~b}$ and $\mathrm{d}$ ). Furthermore, the ratio of hepatocyte proliferation (BrdU-positive cells)/apoptosis (TUNEL-positive cells) decreased significantly in group $\mathrm{M}$ compared with control group $\mathrm{C}(0.10 \pm 0.03$ vs $0.19 \pm 0.03$, respectively, $P<0.01$ ), whereas it increased significantly in group $\mathrm{R}$ compared with group $M(0.41 \pm 0.09, P<0.01$, Figure 5e). In addition, as shown in Figure 5f, mRNA expression of IL-6, which is known to initiate hepatocyte growth through the STAT3 transcription factor, markedly decreased in group M and thereafter increased in group R, whereas STAT-3 expression remained unchanged (data not shown). Furthermore, mRNA expression of BAX and BAK, proapoptotic genes, markedly increased in group $\mathrm{M}$ and returned to the normal range in group $\mathrm{R}$, whereas $\mathrm{Bcl}-\mathrm{xl}$ and $\mathrm{Bcl}-2$ mRNA expression remained unchanged (data not shown). These results suggest that hepatocyte proliferation/apoptosis undergoes a dynamic transition on changing the diet from MCDD to CD.

\section{Involvement of ER Stress in Fibrosis of Steatohepatitis and its Recovery}

Caspase-12 is known as a member of the IL- $1 \beta$-converting enzyme subfamily of caspases. In rodents, the homolog of this gene mediates apoptosis in response to ER stress. Immunohistochemistry using anti-caspase-12 antibodies revealed that caspase-12 showed negligible expression in group $\mathrm{C}$, whereas it was abundant in hepatocytes with fatty degeneration in group $\mathrm{M}$, indicating the occurrence of $\mathrm{ER}$ stress in fatty hepatocytes (Figure 6a). The dietary change clearly reduced the content of caspase-12 in hepatocytes (Figure 6a).

Immunoblot analyses of ER stress-marker proteins such as caspase-12, caspase-7 and cleaved caspase-7, and GRP78 showed that all of these protein expressions were significantly increased in group $\mathrm{M}$ and successively reduced in group $\mathrm{R}$ (Figure $6 \mathrm{~b}$ and $\mathrm{c}$ ). In addition, PDI, an ER-residing protein that catalyzes protein folding and thiol-disulfide interchange reactions, ${ }^{30,31}$ was markedly induced in group $\mathrm{M}$ compared with groups $\mathrm{C}$ and $\mathrm{R}$ (Figure $6 \mathrm{~d}$ ).

RT-PCR analyses supported these observations by showing that mRNAs of GRP78, caspase-12, caspase-7, c-Jun, and 

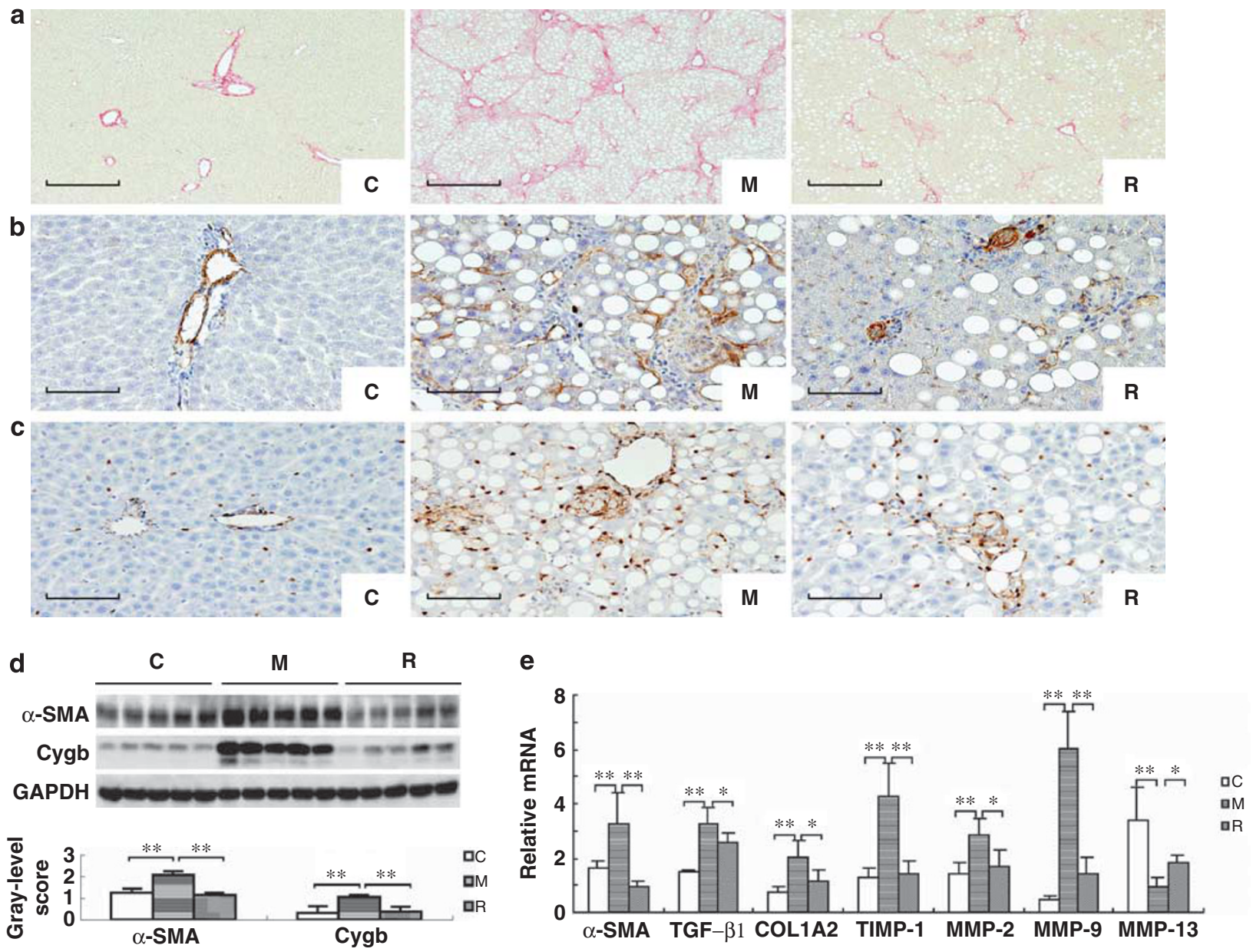

Figure 4 Hepatic stellate cell activation and liver fibrosis. (a) Sirius Red staining $(\times 100)$. Bar, $50 \mu \mathrm{m}$. (b) $\alpha$-SMA immunostaining $(\times 400) . \alpha$-SMA-positivity was seen only around large vessels in group C. In group $M, \alpha$-SMA-positive cells colocalized in and around granulomas close to fatty hepatocytes and perisinusoidal spaces, indicating they were activated stellate cells. The number of $\alpha$-SMA-positive cells was clearly reduced in group R. Bar, $12.5 \mu \mathrm{m}$. (c) Cygb immunostaining $(\times 400)$. Cygb-positivity was seen only along sinusoids in group C. In group M, Cygb-positive cells colocalized in and around granulomas close to fatty hepatocytes and perisinusoidal spaces, indicating that they were activated stellate cells. The number of Cygb-positive cells was clearly reduced in group R. Bar, $12.5 \mu \mathrm{m}$. (d) Immunoblotting for $\alpha$-SMA and Cygb. The gray-level score indicates the histogram of immunoblotting for $\alpha$-SMA and Cygb. ${ }^{*} P<0.01$. (e) Fibrotic gene expressions in the liver determined by qRT-PCR. Relative mRNA levels of $\alpha$-SMA, TGF $\beta 1$, Col1A2, TIMP-1, MMP-2, MMP-9, and MMP-13. mRNA levels were normalized by GAPDH. ${ }^{*} P<0.05$, ${ }^{* * P}<0.01$.

ERp57 increased significantly in group $\mathrm{C}$ and decreased after 2 weeks of $\mathrm{CD}$ diet administration (Figure 6e).

\section{DISCUSSION \\ Hepatic Steatosis: the 'Primer' for Fibrosis of NASH Induced by MCDD}

As both methionine and choline are essential precursors of hepatic phosphatidylcholine synthesis, their deficiency provokes hepatic steatosis by limiting the availability of its substrates, which, in turn, inhibits VLDL assembly and blocks TG secretion from hepatocytes. ${ }^{32,33}$ Our study showed that serum levels of TG and FFA in MCDD-induced fatty liver fibrosis (group M) decreased to one-fifth and twothirds, respectively, of that in the $\mathrm{CD}$ group (group C), indicating the impaired secretion of TG and FFA from hepatocytes. Hepatic steatosis facilitates the mitochondrial uptake of FFA, the overflow of which triggers $\beta$-oxidation, resulting in the generation of reactive oxygen radicals to trigger lipid peroxidation. ${ }^{34,35}$ This leads to the production of toxic substances that damage the mitochondria and stimulate further production of reactive oxygen species. ${ }^{34}$ Such a positive feedback loop results in cellular damage, activation of liver macrophages (Kupffer cells), and generation of proinflammatory cytokines that initiate hepatic inflammation. ${ }^{36,37}$

Kupffer cells could be the main source of TNF- $\alpha$ in MCDD-induced liver injury. In addition, MMP-9 (gelatinase B), a member of MMPs, is derived mainly from Kupffer cells in the liver, ${ }^{38}$ and its expression is significantly increased together with the activation of cells, indicating that MMP-9 could be a marker of Kupffer cell activation instead of its activity as a collagenase. A number of studies have shown increased serum and plasma levels of MMP-9 in various types 


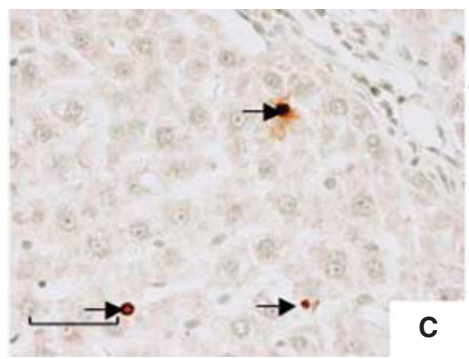

b

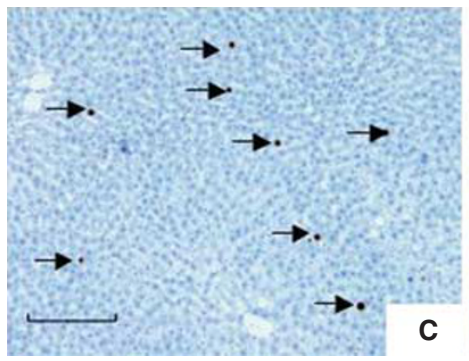

C
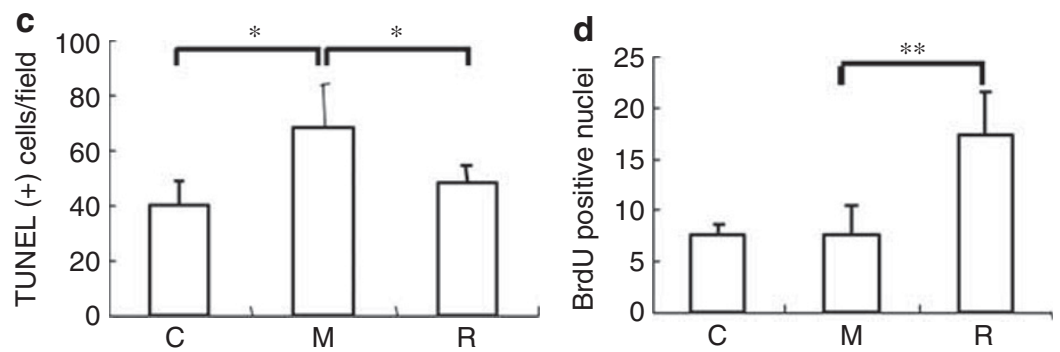

g
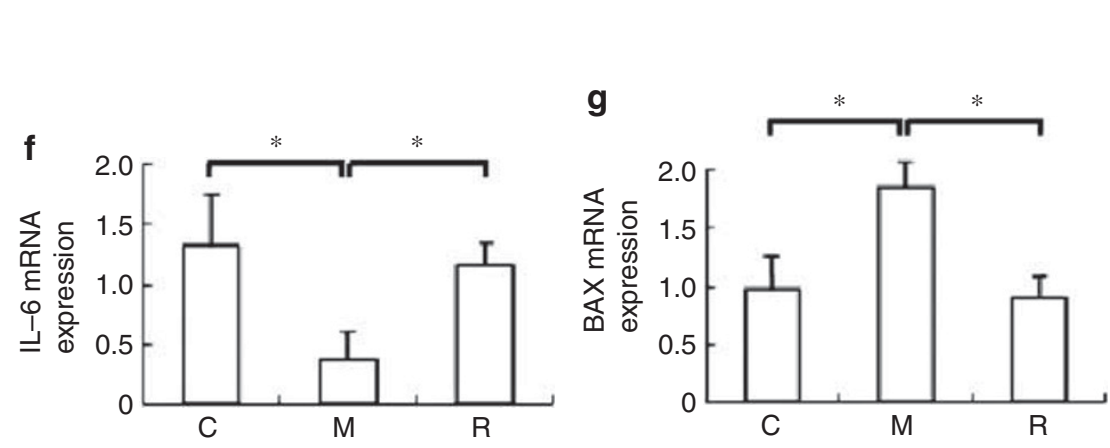
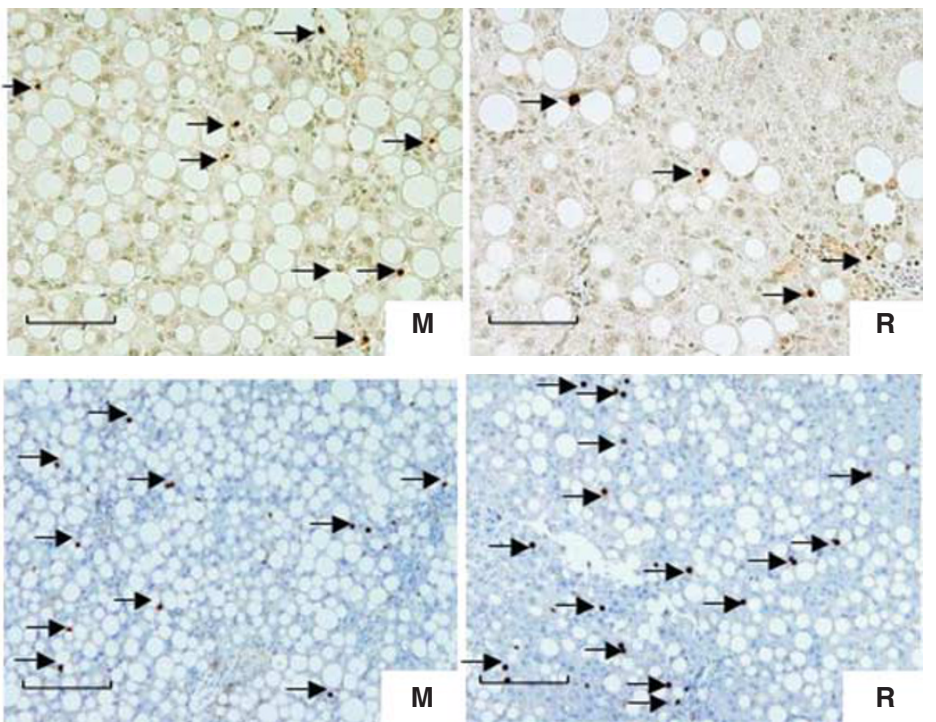
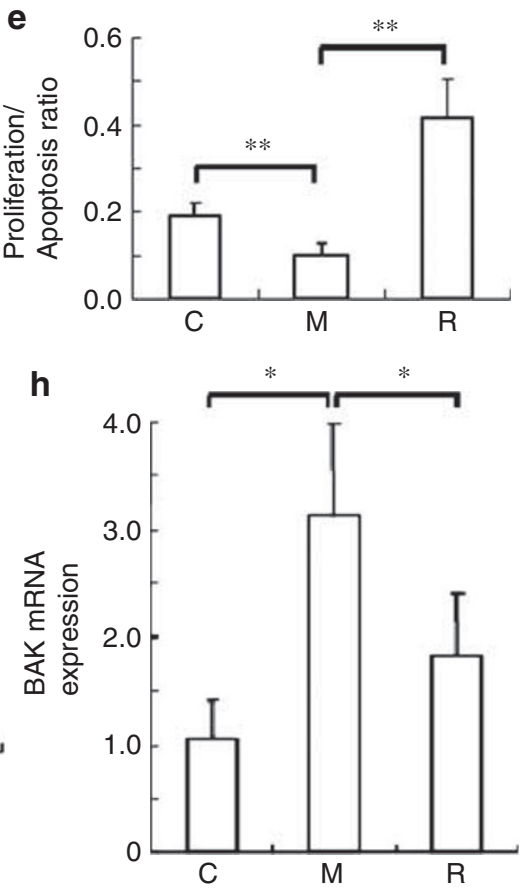

Figure 5 Changes in hepatocyte apoptosis and proliferation. (a) A typical photograph of apoptotic hepatocytes (TUNEL staining, arrows) ( $\times$ 400). TUNELpositive cells were counted under a microscope in $>100$ unselected $20 \times$ microscopic fields per liver. Bar, $12.5 \mu \mathrm{m}$. (b) A typical photograph of proliferating hepatocytes (BrdU staining, arrows) $(\times 200)$. Bar, $25 \mu \mathrm{m}$. (c) Bar graphs indicate the number of TUNEL-positive cells per field. ${ }^{\star} P<0.05$. (d) Bar graphs indicate the number of BrdU-positive cells per field. ${ }^{*} P<0.01$. (e) The ratio of proliferation/apoptosis of hepatocytes. ${ }^{*} P<0.05$. ${ }^{* *} P<0.01$. (f-h) Levels of

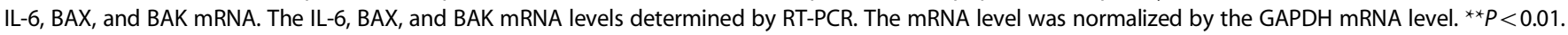

of liver injury, including ischemic reperfusion injury ${ }^{39}$ and chronic viral hepatitis. ${ }^{40,41}$ Furthermore, the mutation of MMP-9 was reported to inhibit hepatic fibrogenesis in mice. $^{42}$ This study showed that MMP-9 and TNF- $\alpha$ mRNA expression increased significantly with the activation of Kupffer cells that were positive for CD68 in group M, whereas switching the diet from MCDD to CD triggered the immediate recovery of MMP-9, suggesting that MMP-9 is associated with the activation status of Kupffer cells.
In contrast, Kupffer cells have been reported to have an important role in the regression of fibrosis through the expression of MMP-13 in other experimental models. ${ }^{43,44}$ The current study showed that the number of CD68- and HO-1positive cells, which are identical to activated Kupffer cells, significantly increased in group M, whereas MMP-13 mRNA expression markedly decreased. Switching the diet from MCDD to CD triggered the immediate recovery of the liver histology, accompanied by a marked increase in the expression 
a
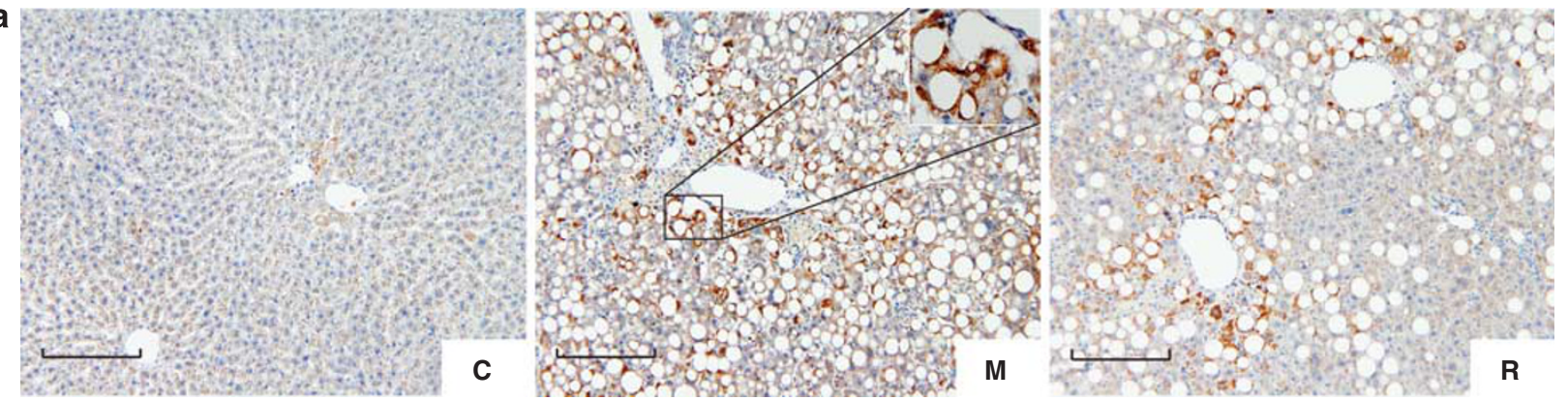

b

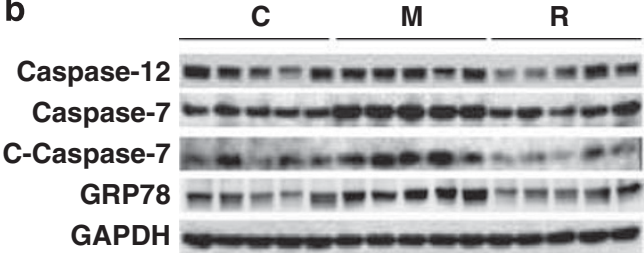

C

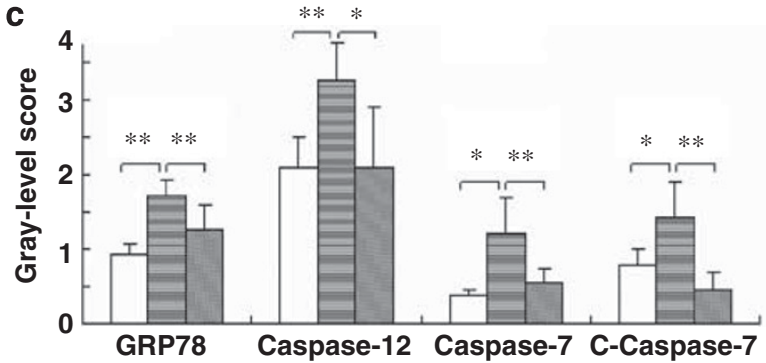

d Protein Disulfide
Isomerase

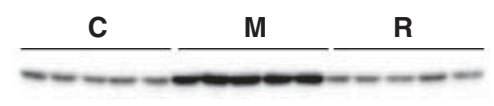

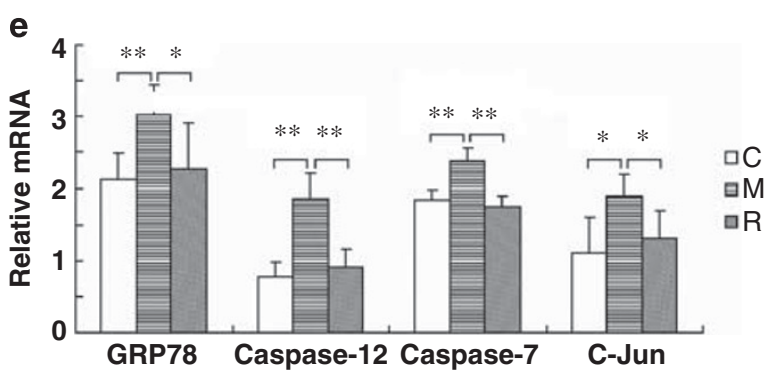
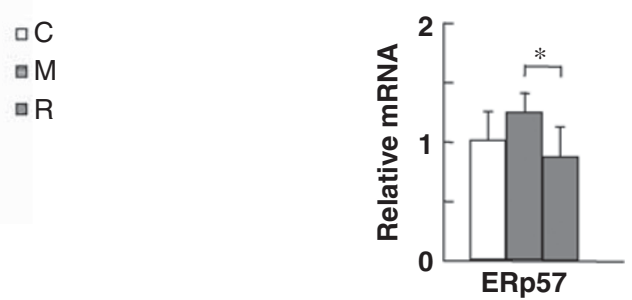

Figure 6 Endoplasmic reticulum stress. (a) Caspase-12 immunostaining. Caspase-12-positive cells were rare in group C, whereas hepatocytes with fatty degeneration exhibited caspase-12 positivity in group $M$. In group R, caspase-12 was retained in hepatocytes with fat, whereas it disappeared in intact hepatocytes. Bar, $25 \mu \mathrm{m}$. The box shows an enlarged view of caspase-12-positive hepatocytes with fatty degeneration. (b) Immunoblotting of caspase-12, caspase-7, cleaved caspase-7, and GRP78. (c) The gray-level score determined by densitometry of the bands on immunoblotting for GRP78, caspase-12, caspase-7, and cleaved caspase-7. (d) Immunoblotting of protein disulfide isomerase. (e) Relative mRNA levels of GRP78, caspase-12, caspase-7, c-Jun, and ERp57 in groups $C, M$, and R. mRNA levels were normalized by GAPDH. ${ }^{*} P<0.05,{ }^{* * P}<0.01$.

of MMP-13 mRNA, indicating the active role of MMP-13 derived from Kupffer cells in the regression of liver fibrosis. ${ }^{45}$

\section{Stellate Cell Activation: a Crucial Role in Fibrosis Development in NASH}

Hepatic stellate cells are present in the normal liver in a quiescent state, and their major function seems to be the storage of vitamin A. After injury, stellate cells activate or trans-differentiate into proliferating myofibroblast-like cells that produce abundant levels of fibrillar collagen and TIMP- $1 .{ }^{46}$ The secretion of abundant levels of TIMP- 1 by activated stellate cells inhibits hepatic collagenase activity, and thereby promotes a net increase in extracellular matrix materials. TIMP-1 also promotes hepatic fibrogenesis by inhibiting the apoptosis of activated stellate cells. ${ }^{47} \mathrm{MMP}-2$ (gelatinase A), derived mainly from activated stellate cells, is involved in degradation of the basement membrane in the early stage of liver fibrosis. ${ }^{48}$ This study showed that both hepatic collagen deposition and stellate cell activation markers, such as $\alpha$-SMA and cytoglobin, increased significantly with a markedly elevated expression of Col1A2, TIMP-1, MMP-2, and TGF $\beta$ - 1 mRNAs. After switching to CD feeding, hepatic collagen deposition decreased significantly, accompanied by the marked reduction of these mRNAs, suggesting that MCDD-induced fatty liver fibrosis was closely related to stellate cell activation.

\section{ER Stress: an Important Participant in Advancement of Liver Fibrosis in NASH}

Obesity is associated with the induction of ER stress predominantly in the liver and adipose tissues. ${ }^{49}$ Previous research has shown that fatty liver induced by a high sucrose 
diet and high saturated fat diet shows clear ER stress events in a rodent model. ${ }^{50}$ In addition, CHOP (a key component in ER stress-mediated apoptosis) deficiency attenuates cholestasis-induced liver fibrosis by reducing hepatocyte injury in bile duct ligation mice. ${ }^{51}$ However, the roles of ER stress in fatty liver induced by MCDD have not been reported. Initial mediators of ER stress responses are ER resident type I transmembrane serine/threonine protein kinases, PKR-like ER kinase, and inositol-requiring enzyme-1(IRE-1); the accumulation of unfolded proteins in ER induces the oligomerization-dependent autophosphorylation of these kinases, ${ }^{52,53}$ and thereby initiates cytoplasmic signal transduction. It was recently shown that activated IRE-1 on the ER membrane recruits TNF receptor-associated factor 2 , and thus activates c-Jun amino-terminal kinase. ${ }^{54}$ In addition, the survival response activates genes that encode ER-residing chaperones such as GRP78/Bip, which uses energy derived from ATP hydrolysis to prevent the aggregation of ER proteins and is considered the classical marker of UPR activation. ${ }^{55}$ The current study showed that the expression of ER stress markers GRP78 (protein and mRNA) and c-Jun mRNA increased significantly in the MCDD group, whereas the expression of all of them decreased markedly after changing the diet. Another ER stress-related molecule, PDI, ${ }^{30,31}$ showed similar behavior (Figure 6d and e). Thus, ER stress may be a key factor in MCDD-induced fatty liver fibrosis.

Caspases also participate in ER stress-induced apoptosis. In mice, procaspase- 12 is localized on the cytoplasmic side of the ER and is cleaved and activated specifically by ER stress, but not by death receptor or mitochondria-mediated apoptotic signals. ${ }^{56}$ Caspase-7, which translocates from the cytosol to the cytoplasmic side of the ER membrane in response to ER stress, has been reported to interact with and cleave procaspase-12, leading to its activation. ${ }^{57}$ Activated caspase12 then cleaves and activates procaspase- 9 , which in turn activates the downstream caspase cascade, including caspase3 , DNA fragmentation, and cell death. ${ }^{58}$ Our results also showed that protein and gene expressions of caspase-12, caspase-7, and cleaved caspase-7 were significantly elevated during steatohepatitis together with the increased number of apoptotic hepatocytes, whereas they were reduced markedly after changing the diet. Furthermore, although the proliferation of hepatocytes did not show a clear change in the MCDD group, the ratio of hepatocyte proliferation/apoptosis decreased significantly, whereas it increased markedly after changing the diet to $\mathrm{CD}$, indicating that the apoptotic caspase-12 pathway may also inhibit hepatocyte proliferation in MCDD-induced steatohepatitis. The marked elevation of BAX and BAK may also participate in stimulating the apoptosis of hepatocytes by MCDD.

In conclusion, this study shows that, although the underlying mechanisms involved in MCDD-induced fatty liver fibrosis are complicated, they may include not only wellknown factors, such as steatosis, oxidative stress, and the activation of Kupffer and stellate cells, but also ER stresses and the balance between hepatocyte proliferation and apoptosis. The reversibility of liver fibrosis is also shown in steatohepatitis, at least in the present MCDD model.

Supplementary Information accompanies the paper on the Laboratory Investigation website (http://www.laboratoryinvestigation.org)

\section{ACKNOWLEDGEMENTS}

NK was supported by a Grant-in-Aid for Scientific Research from the Japan Society for the Promotion of Science through Grant no. 18659214 (2007), by a Grant for Research on Hepatitis from the Ministry of Health, Labour and Welfare (2008), and by a Trust Area Research Grant from Osaka City University (2008). We thank Dr Ryoko Shiga for her valuable discussion about this paper.

\section{DISCLOSURE/CONFLICT OF INTEREST}

The authors declare no conflict of interest.

1. Angulo P. Nonalcoholic fatty liver disease. N Engl J Med 2002; 346:1221-1231.

2. Clark JM, Diehl AM. Hepatic steatosis and type 2 diabetes mellitus. Curr Diab Rep 2002;2:210-215.

3. Festi D, Colecchia A, Sacco T, et al. Hepatic steatosis in obese patients: clinical aspects and prognostic significance. Obes Rev 2004;5:27-42.

4. Bedogni G, Miglioli L, Masutti F, et al. Prevalence of and risk factors for nonalcoholic fatty liver disease: the Dionysos nutrition and liver study. Hepatology 2005;42:44-52.

5. Boccato S, Pistis R, Noventa F, et al. Fibrosis progression in initially mild chronic hepatitis C. J Viral Hepat 2006;13:297-302.

6. Fartoux L, Chazouillères $\mathrm{O}$, Wendum $\mathrm{D}$, et al. Impact of steatosis on progression of fibrosis in patients with mild hepatitis C. Hepatology 2005;41:82-87.

7. Leandro G, Mangia A, Hui J, et al. Relationship between steatosis, inflammation and fibrosis in chronic hepatitis C: a meta-analysis of individual patient data. Gastroenterology 2006;130:1636-1642.

8. Sass DA, Chang P, Chopra KB. Nonalcoholic fatty liver disease: a clinical review. Dig Dis Sci 2005;50:171-180.

9. Bugianesi $\mathrm{E}$, Leone N, Vanni $\mathrm{E}$, et al. Expanding the natural history of nonalcoholic steatohepatitis: from cryptogenic cirrhosis to hepatocellular carcinoma. Gastroenterology 2002;123:134-140.

10. Shimada M, Hashimoto E, Taniai M, et al. Hepatocellular carcinoma in patients with non-alcoholic steatohepatitis. J Hepatol 2002;37: 154-160.

11. Bugianesi E. Review article: steatosis, the metabolic syndrome and cancer. Aliment Pharmacol Ther 2005;22(Suppl 2):40-43.

12. Kelley DE, McKolanis TM, Hegazi RA, et al. Fatty liver in type 2 diabetes mellitus: relation to regional adiposity, fatty acids, and insulin resistance. Am J Physiol Endocrinol Metab 2003;285:E906-E916.

13. Shiratori $Y$, Imazeki $F$, Moriyama $M$, et al. Histologic improvement of fibrosis in patients with hepatitis $C$ who have sustained response to interferon therapy. Ann Intern Med 2000;132:517-524.

14. Poynard T, McHutchison J, Davis GL, et al. Impact of interferon alfa-2b and ribavirin on progression of liver fibrosis in patients with chronic hepatitis C. Hepatology 2000;32:1131-1137.

15. Yuan M, Konstantopoulos N, Lee J, et al. Reversal of obesity- and diet-induced insulin resistance with salicylates or targeted disruption of Ikkbeta. Science 2001;293:1673-1677.

16. Uysal KT, Wiesbrock SM, Marino MW, et al. Protection from obesityinduced insulin resistance in mice lacking TNF-alpha function. Nature 1997;389:610-614

17. Hirosumi J, Tuncman G, Chang L, et al. A central role for JNK in obesity and insulin resistance. Nature 2002;420:333-336.

18. Hampton RY. ER stress response: getting the UPR hand on misfolded proteins. Curr Biol 2000;10:R518-R521.

19. Mori K. Tripartite management of unfolded proteins in the endoplasmic reticulum. Cell 2000;101:451-454.

20. Harding HP, Calfon M, Urano F, et al. Transcriptional and translational control in the mammalian unfolded protein response. Annu Rev Cell Dev Biol 2002;18:575-599. 
21. Ji C, Kaplowitz N. Betaine decreases hyperhomocysteinemia, endoplasmic reticulum stress, and liver injury in alcohol-fed mice. Gastroenterology 2003;124:1488-1499.

22. Rodrigues CM, Ma X, Linehan-Stieers C, et al. Ursodeoxycholic acid prevents cytochrome $c$ release in apoptosis by inhibiting mitochondrial membrane depolarization and channel formation. Cell Death Differ 1999;6:842-854.

23. Pavio N, Romano PR, Graczyk TM, et al. Protein synthesis and endoplasmic reticulum stress can be modulated by the hepatitis $C$ virus envelope protein E2 through the eukaryotic initiation factor 2 alpha kinase PERK. J Virol 2003;77:3578-3585.

24. Tardif KD, Mori K, Siddiqui A. Hepatitis C virus subgenomic replicons induce endoplasmic reticulum stress activating an intracellular signaling pathway. J Virol 2002;76:7453-7459.

25. Kawada N, Kristensen DB, Asahina K, et al. Characterization of a stellate cell activation-associated protein (STAP) with peroxidase activity found in rat hepatic stellate cells. J Biol Chem 2001;276:25318-25323.

26. Nakatani K, Seki S, Kawada N, et al. Expression of SPARC by activated hepatic stellate cells and its correlation with the stages of fibrogenesis in human chronic hepatitis. Virchows Arch 2002;441:466-474.

27. Otogawa K, Kinoshita K, Fujii H, et al. Erythrophagocytosis by liver macrophages (Kupffer cells) promotes oxidative stress, inflammation, and fibrosis in a rabbit model of steatohepatitis: implications for the pathogenesis of human nonalcoholic steatohepatitis. Am J Pathol 2007;170:967-980.

28. Wang YQ, Ikeda K, Ikebe $T$, et al. Inhibition of hepatic stellate cell proliferation and activation by the semisynthetic analogue of fumagillin TNP-470 in rats. Hepatology 2000;32:980-989.

29. Uyama N, Shimahara Y, Okuyama H, et al. Carbenoxolone inhibits DNA synthesis and collagen gene expression in rat hepatic stellate cells in culture. J Hepatol 2003;39:749-755.

30. Riemer J, Bulleid N, Herrmann JM. Disulfide formation in the ER and mitochondria: two solutions to a common process. Science 2009;324:1284-1287.

31. Nakamura T, Lipton SA. Cell death: protein misfolding and neurodegenerative diseases. Apoptosis 2009;14:455-468.

32. Vance JE, Vance DE. The role of phosphatidylcholine biosynthesis in the secretion of lipoproteins from hepatocytes. Can J Biochem Cell Biol 1985;63:870-881.

33. Yao ZM, Vance DE. The active synthesis of phosphatidylcholine is required for very low density lipoprotein secretion from rat hepatocytes. J Biol Chem 1988;263:2998-3004.

34. Fromenty $B$, Robin MA, Igoudjil A, et al. The ins and outs of mitochondrial dysfunction in NASH. Diabetes Metab 2004;30:121-138.

35. Pessayre D, Fromenty B. NASH: a mitochondrial disease. J Hepatol 2005;42:928-940.

36. Albano E, Mottaran E, Occhino G, et al. Review article: role of oxidative stress in the progression of non-alcoholic steatosis. Aliment Pharmacol Ther 2005;22:71-73.

37. Day CP. From fat to inflammation. Gastroenterology 2006;130:207-210.

38. Winwood PJ, Schuppan D, Iredale JP, et al. Kupffer cell-derived 95 kDa type IV collagenase/gelatinase B: characterisation and expression in cultured cells. Hepatology 1995;22:304-315.

39. Kuyvenhoven JP, Verspaget HW, Gao Q, et al. Assessment of serum matrix metalloproteinases MMP-2 and MMP-9 after human liver transplantation: increased serum MMP-9 level in acute rejection. Transplantation 2004;77:1646-1652.

40. Leroy V, Monier F, Bottari S, et al. Circulating matrix metalloproteinases 1, 2, 9 and their inhibitors TIMP-1 and TIMP-2 as serum markers of liver fibrosis in patients with chronic hepatitis C: comparison with PIIINP and hyaluronic acid. Am J Gastroenterol 2004;799:271-279.

41. Chung TW, Kim JR, Suh Jl, et al. Correlation between plasma levels of matrix metalloproteinase (MMP)-9/MMP-2 ratio and alpha-fetoproteins in chronic hepatitis carrying hepatitis B virus. J Gastroenterol Hepatol 2004;19:565-571.

42. Roderfeld $M$, Weiskirchen $\mathrm{R}$, Wagner $\mathrm{S}$, et al. Inhibition of hepatic fibrogenesis by matrix metalloproteinase- 9 mutants in mice. FASEB J 2006;20:444-454.

43. Hironaka K, Sakaida I, Matsumura Y, et al. Enhanced interstitial collagenase (matrix metalloproteinase-13) production of Kupffer cell by gadolinium chloride prevents pig serum-induced rat liver fibrosis. Biochem Biophys Res Commun 2000;267:290-295.

44. Sakaida I, Hironaka K, Terai S, et al. Gadolinium chloride reverses dimethylnitrosamine (DMN)-induced rat liver fibrosis with increased matrix metalloproteinases (MMPs) of Kupffer cells. Life Sci 2003;72:943-959.

45. Friedman S. Mac the knife? Macrophages — the double-edged sword of hepatic fibrosis. J Clin Invest 2005;115:29-32.

46. Iredale JP, Benyon RC, Arthur MJ, et al. Tissue inhibitor of metalloproteinase-1 messenger RNA expression is enhanced relative to interstitial collagenase messenger RNA in experimental liver injury and fibrosis. Hepatology 1996;24:176-184.

47. Iredale JP, Murphy G, Hembry RM, et al. Human hepatic lipocytes synthesize tissue inhibitor of metalloproteinases-1. Implications for regulation of matrix degradation in liver. J Clin Invest 1992;90:282-287.

48. Winwood PJ, Schuppan D, Iredale JP, et al. Kupffer cell-derived 95-kd type IV collagenase/gelatinase $\mathrm{B}$ : characterization and expression in cultured cells. Hepatology 1995;22:304-315.

49. Ozcan U, Cao Q, Yilmaz E, et al. Hotamisligil. Endoplasmic reticulum stress links obesity, insulin action, and type 2 diabetes. Science 2004;306:457-461.

50. Wang D, Wei Y, Pagliassotti MJ. Saturated fatty acids promote endoplasmic reticulum stress and liver injury in rats with hepatic steatosis. Endocrinology 2006;147:943-951.

51. Tamaki N, Hatano E, Taura K, et al. CHOP deficiency attenuates cholestasis-induced liver fibrosis by reduction of hepatocyte injury. Am J Physiol Gastrointest Liver Physiol 2008;294:G498-G505.

52. Bertolotti A, Zhang $Y$, Hendershot LM, et al. Dynamic interaction of BiP and ER stress transducers in the unfolded-protein response. Nat Cell Biol 2000;2:326-332.

53. Liu CY, Schröder M, Kaufman RJ. Ligand-independent dimerization activates the stress response kinases IRE1 and PERK in the lumen of the endoplasmic reticulum. J Biol Chem 2000;275:24881-24885.

54. Urano F, Wang X, Bertolotti A, et al. Coupling of stress in the ER to activation of JNK protein kinases by transmembrane protein kinase IRE1. Science 2000;287:664-666.

55. Iwawaki T, Hosoda A, Okuda T, et al. Translational control by the ER transmembrane kinase/ribonuclease IRE1 under ER stress. Nat Cell Biol 2001;3:158-164.

56. Nakagawa T, Yuan J. Cross-talk between two cysteine protease families. Activation of caspase- 12 by calpain in apoptosis. J Cell Biol 2000;150:887-894.

57. Rao RV, Hermel E, Castro-Obregon S, et al. Coupling endoplasmic reticulum stress to the cell death program: mechanism of caspase activation. J Biol Chem 2001;276:33869-33874.

58. Tan Y, Dourdin N, Wu C, et al. Ubiquitous calpains promote caspase-12 and JNK activation during endoplasmic reticulum stress-induced apoptosis. J Biol Chem 2006;281:16016-16024. 